\title{
Study on the Planning of Urban Agricultural Tourism Park in Xi'an Around Mountain Tourism Zone
}

\author{
Xubang Wang ${ }^{1, a}$ \\ ${ }^{1}$ Shaanxi Normal University, Xi’an, Shaanxi, 710062
}

\author{
Keywords: Xi’an, Tourism Park, Urban Agricultural Tourism, Planning Study
}

\begin{abstract}
Urban agriculture is not a new concept. More than 100 years ago Howard's theory of pastoral city implied the seeds of urban agriculture. Today, urban agriculture in developed countries and regions, especially in developed countries and regions, often play an important role in urban development, Its theoretical research and practice forms are also rich and varied. In the face of shortage of resources, climate change and a series of urban and rural problems facing our country in the background, the discussion of urban agriculture is particularly important.
\end{abstract}

\section{Introduction}

With the economic development and social progress, as well as the rapid population growth, resources and environmental pressures are also growing. Not only that, the rapid development of urbanization process has long been far beyond the load of urban land, the rapid development of extensive economy led to the waste of resources and shortages, the environment has also been a serious damage and pollution. The increasing urban scope makes the scope of agricultural land smaller and smaller, and the fertile land on the edge of the city is increasingly spreading to the spread of the city. This situation seriously undermines the theoretical guidance of today's sustainable development path, today, serious environmental pollution damage, increasing the number of cultivated land, the decline in physical quality and other social problems. In this social background, the natural dependence on nature of the traditional agricultural production, with the rapid economic and technological development has gradually from the primary industry to the second and tertiary industries to enhance the agricultural production mode of efficient income The How to achieve the sustainable development of natural resources and natural environment in a limited land area depends on whether the mode of production of agriculture is reasonable to the extent that land use is becoming scarce today.

\section{Urban Agriculture Park Concept}

"Urban agriculture" English original meaning refers to the metropolitan area of farmland operations, it is close to the city, in urban and rural areas of the development of fuzzy areas, but also for the public to provide good agricultural and sideline products and beautiful ecological environment of high-density, multi-functional agriculture. Urban agriculture can not only provide agricultural products, but also for people to leisure travel, feel the agriculture and understanding of rural areas. In the foreign countries because of the development of agriculture and spatial distribution pattern is different, so the concept of urban agriculture theory research in the regional, social background and economic background under the influence of different understanding of the current foreign more authoritative theory The views of the Japanese scholar Qing Lu Shiro, Qiao Ben Zhuoer, American scholar EF Hugh Maha and the Food and Agriculture Organization of the United Nations and the Development Program. The definition of urban agriculture was first proposed by the Japanese geography and economist Qinglu Shiro in the 1930s in his book "Agricultural Economic Geography". He believes that the geographical distribution of urban agriculture in the geographical distribution of urban agriculture is more distributed in the urban circle of commercial and industrial areas; in the product category, urban agriculture mainly to provide daily consumption of food and agricultural products, its professional, urban The degree of 
industrialization is more complicated and there are more complex production characteristics. At the same time, urban agriculture has a significant dependency on its economy, and its area is two or three times larger than that of the general city. Qiao Benchaoer's view is that with the process of urbanization and the formation of the new agricultural form of urban agriculture, it is vulnerable to the impact of urban expansion, generally located in the city, of course, also benefit from the city infrastructure is complete. American economist Omar E.F. that urban agriculture is located in the urban areas, is the organic connection between man and nature, and continuously meet the basic needs of human production and improve the form of human living environment, the form of agricultural development. According to the Food and Agriculture Organization of the United Nations and the Development Program, urban agriculture refers to agriculture in the city and its surrounding urban agglomerations, which is the urban leisure space, including arable land, mountains and water, etc. The farming and aquaculture industry provides fresh produce for the city and Eco-city, leisure and tourism and other modern agriculture.

\section{Status of Agricultural Park in Xi'an Metropolitan Area}

At present, in the metropolitan area with the rise of urban agriculture caused by the phenomenon of agricultural parks everywhere, most of the park in the early lack of detailed analysis of the natural ecological resources and the park's own advantages of agricultural resources and other factors of competitiveness analysis. The biggest advantage of the urban agricultural park is that it can rely on the modern development of modern agriculture in the form of advanced, through the analysis of agricultural location of their own location delineation of agricultural development within the location, and further in the agricultural area through the detailed landscape design of the agricultural park Of the building, can only be developed in the local area with a demonstration function, radiation function, educational functions, tourism and tourism functions of the successful park. However, some small and medium-sized agricultural park only immediate interests, in the absence of scientific planning in the case of blind site development, in the early and no systematic basis for the natural ecosystem of the base of a detailed investigation and analysis, but also the lack of local city The deep excavation of agricultural resources and the integration of relevant regional culture and other elements, that is, the whole is not the park itself will be the construction and development of objective project content and construction form to make the right planning. In the case of such a lack of preparation, the blind construction of the park, such a lack of scientific and rational planning will inevitably lead to the park land resources waste, so that the park itself has only basic service functions, and failed to build a sustainable Development of modern agricultural demonstration park.

Xi'an metropolitan area within the small and medium-sized agricultural park, early due to the lack of positioning of their own park location and the lack of appropriate research and analysis, so there has been the form of garden copy, "thousands of side" phenomenon. At the same time, the park is also a lack of innovative features within the project, the project partition is more vague, single, can not long-term park to maintain long-term profit development. Most of the agricultural park lack of systematic landscape design, but in the park on the basis of the site set up some of the so-called ancient style of the landscape to create a sketch, the park within the landscape design can not be called the design, it is only a Simple copy and imitation, this blind copy of the rough means so that the park can not show their own charm, to cover the region within the region with the characteristics of the characteristics of agricultural landscape and unique regional cultural atmosphere, but to cover the charm of the park landscape characteristics "Fake". Will eventually make the park in the establishment, resulting in tourists in the garden process in the boring and even boredom, which lost the attractiveness of tourists and their own competitiveness; the same time, in the author's research process found that most of the agricultural park Landscape pattern and spatial form of the phenomenon of convergence is more serious, geographical location is relatively similar to the area of agricultural park landscape construction is generally similar to the internal function of tourism projects such as the general convergence, landscape quality is low, redundant construction and other phenomena is particularly serious. For example: the entrance to the park in order to reflect 
the style of its pastoral scenery, without exception, set up for the wooden arch or gatehouse, this form from the beginning of the entrance is only a blind form of landscape imitation and copying, the internal landscape to create And the form of architectural form is not consistent with the style of Xi'an city circle style.

\section{Research on Planning Strategy of Urban Agriculture Park}

The contents of the landscape design of the urban agriculture park mainly include the following aspects: the basic ecological ecosystem and the current situation data collection and stacking analysis, the spatial pattern of the park area, the overall function of the park location, functional zoning, park land use planning, park Road traffic streamline design, landscape zoning node planning and design, landscape supporting facilities planning and design aspects of which urban agriculture park is different from the scenic area planning and design content is important point is that the urban agricultural park is the main purpose of agricultural income, So the production of cultivated planning area is its important landscape zoning, I believe that it as an important landscape partition is included in the landscape partition node planning and design, so will be described in the following description of the landscape partition node design content The

Although agricultural production in urban agro-parks is generally not carried out in rural areas, urban agriculture is closely related to rural impressions and rural landscapes, which is often the source of leisure value for urban agriculture. In other words, the city crowd for the urban agricultural park yearning is not just the demand for agricultural products, more rural natural ecology to attract and rural life yearning. Therefore, the characteristic of the first urban agricultural park is the rural nature, rural and its other urban leisure industry is the main difference.

Another major feature of the urban agricultural park is its "local character", the park often need to show its unique geographical features and regional culture. Regional as the main features of its leisure products to attract consumers, rather than the general leisure industry only emphasizes the effect of the product. Such as Disney Land, visitors are in Florida, Los Angeles, or in Tokyo, Hong Kong's Disneyland, the leisure experience is basically the same. Therefore, the urban agricultural park needs to fully tap the local landscape characteristics, customs and so on, the park itself can not be copied, otherwise it will be difficult to ensure its long-standing value.

Agriculture since ancient times has been called "rely on the day to eat" industry, showing its close ties with the natural ecology. Whether it is natural ecosystems or urban ecosystems, agricultural production is taken for nature, and will be fed back to the natural ecological cycle, so ecology is also an important attribute of urban agriculture. Some other types of urban leisure industry are often associated with natural ecology, and some are even antisocial. And urban agriculture can not save its natural and cultural ecological attributes, will also violate the nature of its agricultural production, so that the impact of the development of the park.

Agriculture has been able to transition to the leisure industry, in addition to its rural nature, regional, ecological characteristics, but also its unique production process and has the attraction. Not only in the mechanical, rigid industrial production and production, but also different from other services at your fingertips, the agricultural production process for most of the agricultural and rural life has been out of the urban population itself has a great life experience incentives. Some domestic food service only to the primary form of the development of urban agricultural park is difficult to expand the market and maintain long-term development also shows the lack of experience of leisure content, and replaced by the desire to meet the desire of consumption will only accelerate the deterioration of urban agricultural park Thus losing the market value of experience in urban agriculture itself. 


\section{Conclusion}

This paper takes the urban agriculture park as the research object and takes the landscape design of the Xi'an urban agglomeration as the main line. In view of the current situation of the landscape construction in the agricultural park within the Xi'an metropolitan area, from the point of view of landscape design and the landscape planning of the agricultural park and the relevant theories of landscape ecology, landscape aesthetics, tourism and so on. The empirical research is carried out on the urban agro-industrial park in the developed areas and the agricultural park in Xi'an metropolitan area.

\section{Acknowledgements}

Shaanxi Province Department of Education 2014 issue "Xi'an city tourism around the city of agricultural tourism problems to be solved" No.: 14JK2136

\section{References}

[1] Zhang Yichuan. Study on Landscape Planning Evaluation of Urban Leisure Agriculture Park [J].Journal of Hubei Agricultural Sciences, 2013 (01)

[2] Chen Xuming. Guangzhou development and construction of urban vertical farm prospects [J] .Guangdong Agricultural Sciences, 2012 (17)

[3] Zhang Yunpeng, Zou Zhiren. Local Culture Green Soul - A Case Study of the Planning and Design of Modern Agricultural Demonstration Area in Xi'an White Deer Plateau [J]. Journal of Northwest Forestry College, 2007 (02)

[4] Liu Wan. To promote the development of urban agriculture in rural areas: the concept of observation and thinking [J]. Urban Development Research, 2009 (09)

[5] Han Miao. Study on landscape planning and design of sightseeing agriculture park [J]. Journal of Shaanxi Normal University (2009) 